\title{
Spread of Enterococcal Surface Protein in Antibiotic Resistant Entero- coccus faecium and Enterococcus faecalis isolates from Urinary Tract Infections
}

\author{
Hossein Samadi Kafil ${ }^{1}$ and Ashraf Mohabati Mobarez ${ }^{2, *}$ \\ ${ }^{I}$ Drug Applied Research Center, Tabriz University of Medical Sciences, Tabriz, Iran \\ ${ }^{2}$ Department of Medical Bacteriology, Faculty of Medical Science, Tarbiat Modares University, Tehran, Iran
}

\begin{abstract}
Enterococci rank among leading cause of nosocomial bacteremia and urinary tract infection in hospital and community acquired infections. Several traits that may contribute to enhanced virulence have been identified in Enterococci. Extracellular surface protein (Esp) is a virulence factor that contributes in biofilm formation and resistance to environmental stresses. In this study we aimed to determine occurrence of esp in E. faecium and E. faecalis isolates isolated from urinary tract infections and to investigate whether there is any correlation between presence of $e s p$ and antibiotic resistance. One hundred and sixty six isolates were collected from patients with UTI and after identification by biochemical and PCR, antibiotic resistances were examined. The presence of esp was investigated by primer-specific PCR. $43.3 \%$ of isolates identified as E. faecium and $56.7 \%$ as E. faecalis. The esp gene was found in $76.1 \%$ of E. faecium isolates and $77.9 \%$ of $E$. faecalis isolate. There were significant correlation between esp positive E. faecium and resistance to Vancomycin $(\mathrm{p}<0.01)$, also in E.faecalis we found correlation between esp positive and resistance to Ampicillin, Chloramphenicol and Tetracycline ( $<<0.01, \mathrm{p}<0.01, \mathrm{p}<0.01$ respectively). Occurrence of $e s p$ in our isolates from urinary tract infection was high that indicates importance of this gene in urinary tract infections and shows importance of ability to forming biofilm and hydrophobicity of surface of Enterococci for causing urinary infection by Enterococci. Also, our finding showed significant correlation between resistance to antibiotics and presence of esp in Enterococci.
\end{abstract}

Keywords: Antibiotic resistance, e. faecium, e. faecalis, esp, urinary tract infection.

\section{INTRODUCTION}

For many years Enterococci species believed to be harmless and considered medically unimportant, because they produce bacteriocins, and they have been used in food industry as starter for dairy products and probiotic [1], but recently Enterococci have been emerged as an important nosocomial pathogens and are among the most frequently isolated organisms in hospital-acquired infections [2]. At present Enterococci is known as important nosocomial infections such as endocarditis [3] bacteremia [3, 4] and urinary tract infections [5]. The majority of enterococcal infections are caused by E. faecalis. However, in parallel with the increase in nosocomial Enterococci infections, a partial replacement of E. faecalis by E. faecium took place in the world [6, 7]. Little is known about enterococcal properties which make it possible for the bacteria to adhere and colonize the host tissue [8]. Several traits that may contribute to enhanced virulence have been identified in Enterococci, but better understanding of the virulence of Enterococci is necessary to control further spread and developing new treatment strategies [6].

*Address correspondence to this author at the Department of Medical Bacteriology, Faculty of Medical Science, Tarbiat Modares University, P.O.Box: 14115-111, Tehran, Iran; Tel: +982182883862;

Fax: +982182884555; E-mail: mmmobarez@modares.ac.ir
Extracellular surface protein (esp) is a cell wall associated protein first described in Enterococcus species by Shankar et al. [9]. It is thought to promote adhesion, colonization and evasion of the immune system, and to play some role in antibiotic resistance [1]. It has also contributions in biofilm formation of Enterococci, which lead to resistance to environmental stresses, and adhesion to eukaryotic cells, such as those of the urinary tract [10]. Shankar et al. showed contribution of esp in the persistence of Enterococci in the animal model of urinary tract infections [11]. In this study we aimed to determine presence of esp gene in E. faecium and E. faecalis isolated from urinary tract infections and to investigate any relationship between presence of esp gene and rate of antibiotic resistance.

\section{MATERIALS AND METHODS}

\section{Study Design}

One hundred and sixty six clinical isolates of Enterococci were collected from patients with urinary tract infections. The isolates were identified as Enterococci and specified by biochemical tests [12]. Identification was confirmed by Mass Spectrophotometer (MALDI-TOF MS microflex, 2012 bruker, Germany) and PCR (as described below). Antibiotic resistance properties of strains were examined by kerbybauer method according to CLSI guideline (CLSI M100S24) [13]. 


\section{DNA Extraction and PCR}

DNA extraction was done by Cinnapure ${ }^{\mathrm{TM}}$ DNA extraction kit (Cinnagen, Iran). Briefly, bacterial pellet was resuspended in $100 \mu \mathrm{l}$ gram positive prelysis buffer and added $20 \mu 1$ lysosyme and incubated at $37^{\circ} \mathrm{C}$ for at least 30 min. After adding lysis buffer and precipitation solution, the solution was transferred to a spin column and after washing the spin, DNA was eluted by elution buffer in $65^{\circ} \mathrm{C}$ [14]. PCR was performed in $25 \mu \mathrm{l}$ volumes that contained 20200ng DNA, $0.5 \mu \mathrm{M}$ of specific primers for E. faecalis ddlE1:ATCAAGTACAGTTAGTCTTTATTAG ddIE2: ACGATTCAAAGCTAACTGAATCAGT) [15], E. faecium (ddIF1: TTGAGGCAGACCAGATTGACG, ddIF2: TATGACAGCGACTCCGATTCC) [16] and for esp (espA: GGAACGCCTTGGTATGCTAAC, espB: GCCACTTTATCAGCCTGAACC) [9] with $1.5 \mathrm{mM} \mathrm{MgCl} 2,200 \mu \mathrm{M}$ of each dNTP, 1X PCR buffer and 2 U DNA polymerase (Cinnagen, Iran). DNA was amplified by general PCR. An initial denaturation of $10 \mathrm{~min}$ at $94^{\circ} \mathrm{C}$ was followed by 35 cycles of denaturation at $94^{\circ} \mathrm{C}(1 \mathrm{~min})$, annealing at $58^{\circ} \mathrm{C}$ for $1 \mathrm{~min}$ and extension at $72^{\circ} \mathrm{C}$ for $1 \mathrm{~min}$, followed by a final extension at $72^{\circ} \mathrm{C}$ for $10 \mathrm{~min}$. product length were $941 \mathrm{bp}$ for E. faecalis, $658 \mathrm{bp}$ for E. faecium and $95 \mathrm{bp}$ for esp. Positive control for PCR were E. faecalis MMH594 (also esp positive), E. faecalis 29212, E. faecium C38 and C68. Negative controls consisted of the PCR components on reaction mixtures lacking Enterococci DNA. PCR products were electrophoreses in $1.5 \%$ agarose gels and after staining with $0.5 \mu \mathrm{g} / \mathrm{ml}$ ethidium bromide visualized under UV light. The size of fragments was determined in comparision with 100bp DNA ladder plus size marker (Fermentas., Germany).

\section{Statistical Analysis}

Chi-square test (or Fisher exact test) was performed for data analysis. $P$ values below 0.05 were considered to be significant. Statistical analysis was done by Spss. 21 software.

\section{Results}

From 166 clinical isolates of urinary tract infections of Enterococci, $59.7 \%$ of isolates were from females and $40.3 \%$ from males. By biochemical differentiation and PCR for specific genes, $43.3 \%$ of isolates were identified as $E$. faecium and $56.7 \%$ as E. faecalis. Antibiotic resistance of strain described by disc diffusion (Figs. 1 and 2) and the presence of esp gene was identified in $77.1 \%$ of all isolates of Enterococci. esp gene was identified in $76.1 \%$ of $E$. faecium and $77.9 \%$ of E. faecalis isolates (Fig. 3). There was not any significant difference between presence of esp gene in E. faecalis and E. faecium isolates ( $\mathrm{P}>0.05)$. Correlation of resistance to antibiotic and presence of the esp genes was investigated. In E. feacium, correlation was found between presence of the esp and resistance to Vancomycin $(\mathrm{p}<0.01)$ (Fig. 1). In E. faecalis we revealed correlation between resistance to Ampicillin, Chloramphenicol and Tetracycline $(\mathrm{p}<0.01, \mathrm{p}<0.01$ and $\mathrm{p}=0.006$ respectively) and presence of esp gene (Fig. 2).

\section{DISCUSSION}

In the previous studies, several investigators have focused on the relationship between Enterococci esp gene and antibiotic resistance. The current investigation examined the relationship of Enterococci esp gene with antibiotic resistance of isolates from in the urinary tract infection. In this study we investigated the presence of esp in E. faecium and E. faecalis isolates from urinary tract infection. Enterococcal surface protein $(e s p)$ is considered as virulence factor in Enterococci, a few studies have done on presence and importance of esp on urinary tract infection of Enterococci. esp has been identified in E. faecium and E.

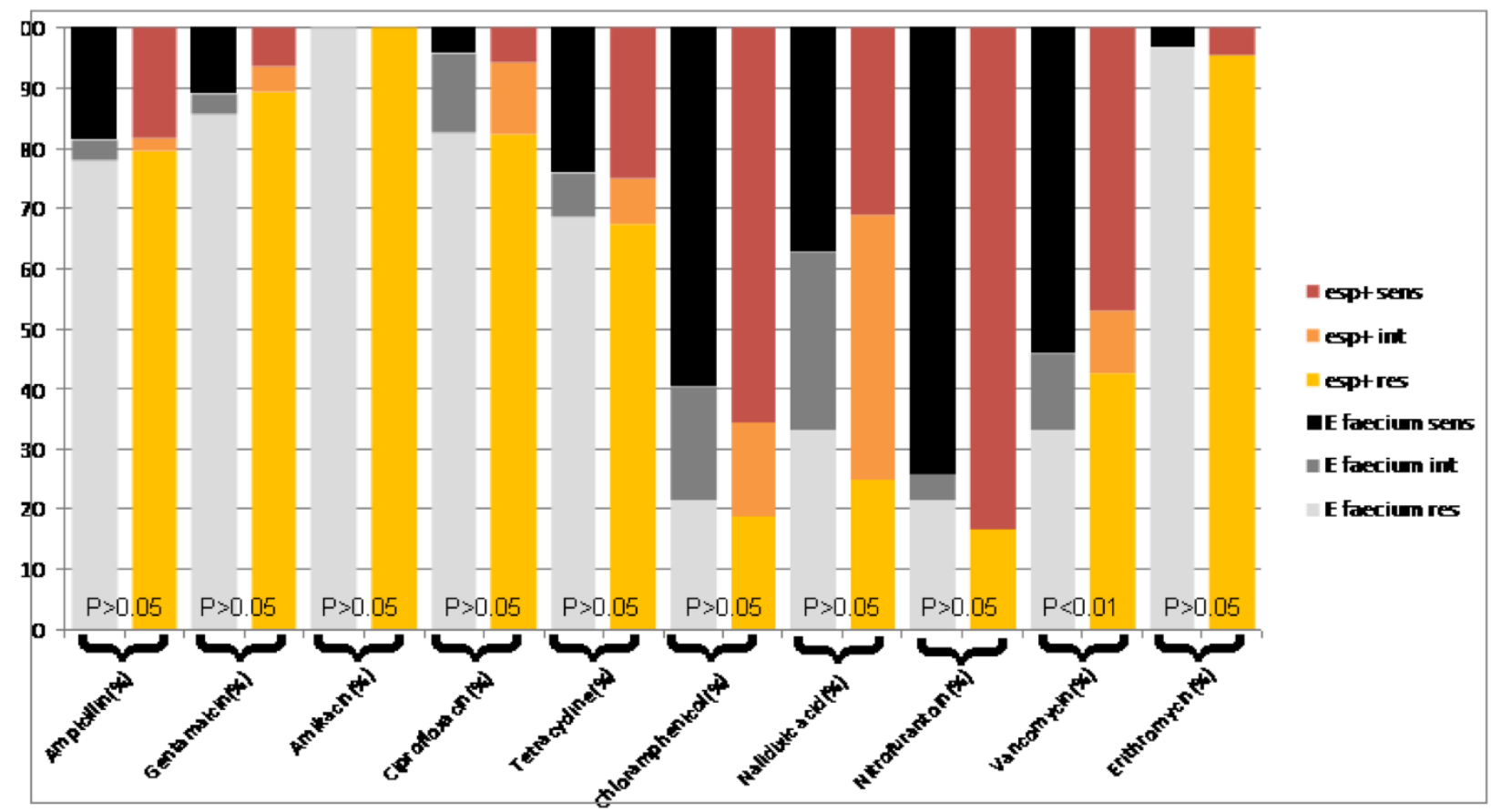

Fig. (1). E. faecium Antibiotic resistance properties in Total and Esp positive strains. Sens: Sensitive; int: intermediate; res: resistance. 


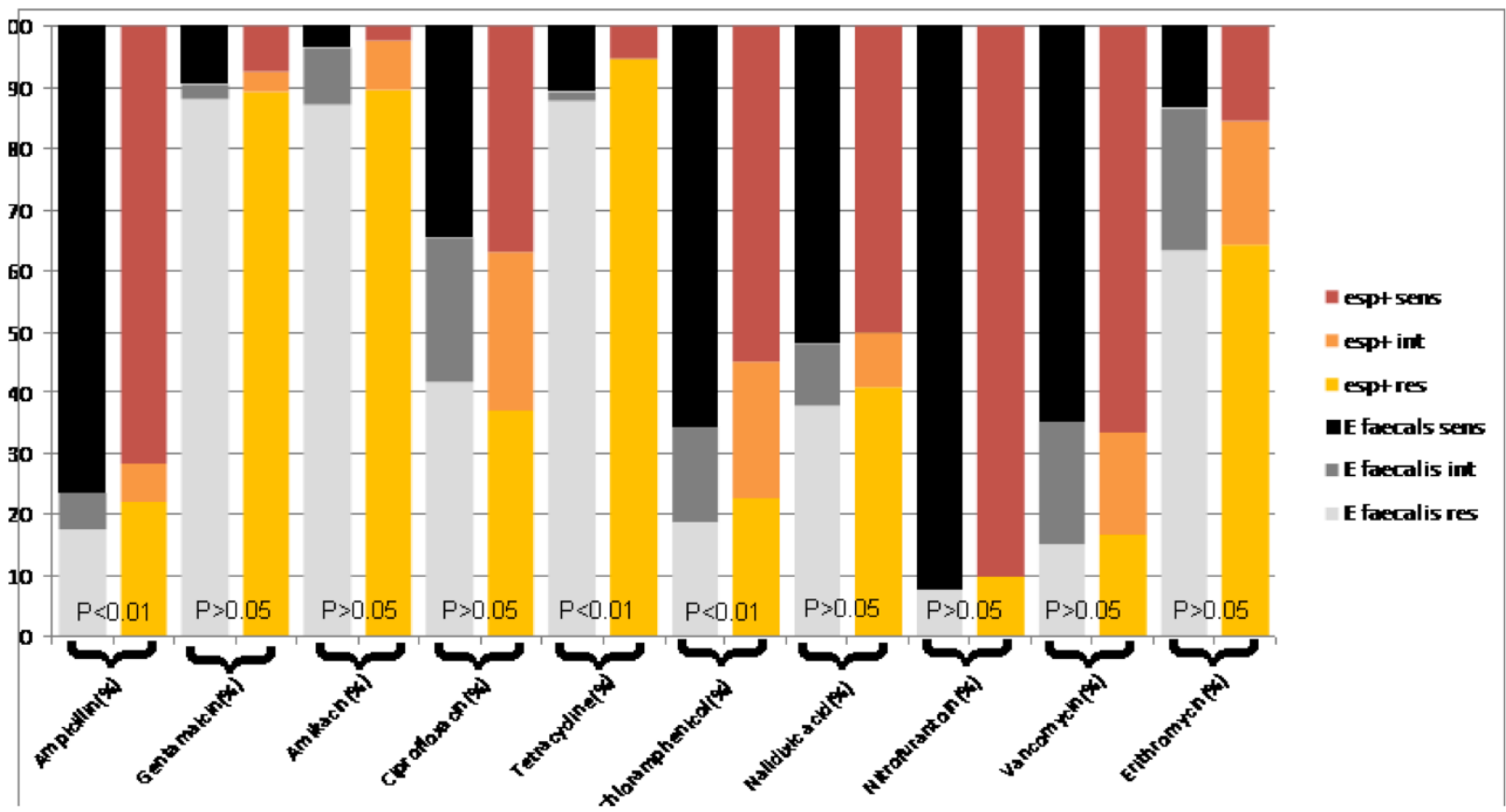

Fig. (2). E.faecalis Antibiotic resistance properties in Total and Esp positive strains. Sens: Sensitive; int: intermediate; res: resistance.

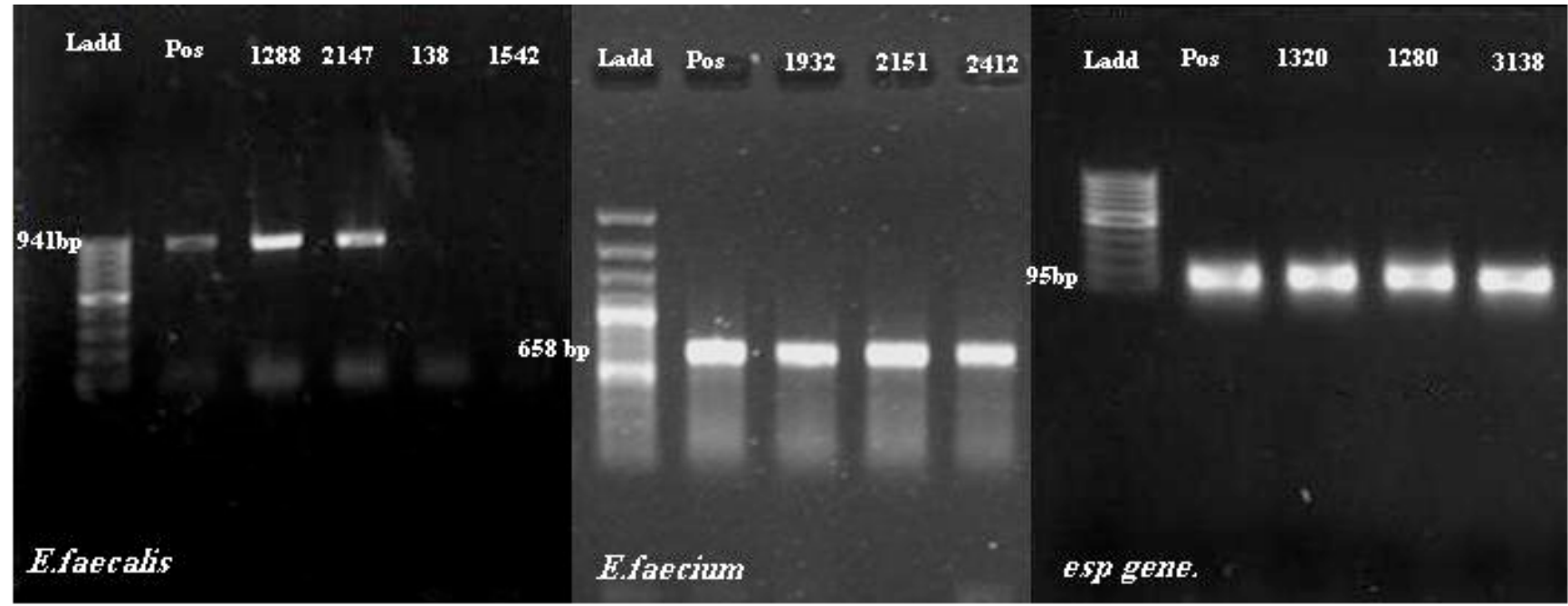

Fig. (3). PCR amplification and screening of Sample for presence of genome. Numbers intended in pictures are patients' numbers and have not any meaning. Positive controls were E. faecalis 29212 (Standard for E.faecalis), E. faecium C38 (Standard for E. faecium) and E. faecalis MMH594 (Standard for esp).

faecalis previously [17], but not in other Enterococci [18]. We revealed high frequency of esp genes in both E. faecium and E. faecalis $(76.1 \%, 77.9 \%$ respectively) isolated from urinary tract infection. It was higher rate than reported in previous studies on clinical samples [17, 19]. esp has been reported as the first important gene for biofilm formation in Enterococci $[6,9]$. The ability to form biofilm on abiotic surfaces is considered to be an important virulence property of the Enterococci [20], biofilm is an assemblage of microbial cells associated with a surface and enclosed in a matrix of primarily polysaccharide material [16]. Defined architecture of the biofilm provides an optimal environment for the exchange of genetic material between bacteria and increases the innate resistance of the bacterium to antibiotic and activities of the host immune response [6, 21]. esp gene positive isolates were considered as expressing the esp protein $[9,22]$. Results of this study shows importance of the biofilm formation and the presence of esp in clinical samples, especially in the urinary tract infections. The nature of urinary tract infections necessitate biofilm for bacteria, and presence of esp in most of urinary cultured Enterococci endorse importance of this gene for survival of bacteria in urinary tract. It has been also demonstrated that esp increased the hydrophobicity of bacterial surface [23]. Therefore, it can help Enterococci to match with urinary tract condition.

In this study, we found significant correlation between the presence of esp and the antibiotic resistance. Our data 
showed significant correlation between presence of esp gene and resistance to Vancomycin in E. faecium (Fig. 1) and resistance to Ampicillin, Chloramphenicol and Tetracycline $(\mathrm{p}<0.001, \mathrm{p}<0.001, \mathrm{p}<0.001)$ (Fig. 2) in E. faecalis. In a study by Billstrom et al, they revealed strong correlation between esp carriage and antimicrobial resistance to Ampicillin and Ciprofloxacin and Imipenem in clinical blood culture isolates of E. faecium [24]. But in our urinary tract isolates of E. faecium, we didn't find similar correlation (Fig. 1). However, we found significant correlation with resistance to Vancomycin and presence of esp. Also in $E$. faecalis isolates we had significant correlation between the presence of esp and resistance to the Ampicillin, Tetracycline and Chloramphenicol (Fig. 2).

In conclusion, our finding provides additional evidence for the presence of esp in Enterococcus isolates from urinary tract infection and high rate of antibiotic resistance may lead to strong biofilm formers and strong adherent to host cells. These three factors may play an important role in enterococcal infections. The presence of these bacteria in urinary tract infection in addition to its multi resistance, close attention should be given to these strains in order to reduce risk for development of disease caused by Enterococci in other areas of the body. Furthermore, additional studies about role of esp expression on biofilm formation of enterococci is needed.

\section{CONFLICT OF INTEREST}

The authors confirm that this article content has no conflict of interest.

\section{ACKNOWLEDGMENTS}

We would like to thank all staff of educational hospitals for cooperation in collecting samples and antibiogram of isolates. Also we thank Dr. Hossein Navidinia for their helpful comments on manuscript.

\section{FUNDING}

This study was granted by Iran National Elite foundation for Hossein Samadi Kafil.

\section{REFERENCES}

[1] Foulquié Moreno MR, Sarantinopoulos P, Tsakalidou E, et al. The role and application of enterococci in food and health. Int J Food Microbiol 2006; 106:1-24.

[2] Emori TG ,Gaynes RP. An overview of nosocomial infections, including the role of the microbiology laboratory. Clin Microbiol Rev 1993; 6: 428-42.

[3] Benes J, Pícha D, Kabelková M, et al. Infective endocarditis caused by unusual gram-positive pathogens. Folia Microbiol (Praha) 2002; 47: 737-41.

[4] Vergis EN, Shankar N, Chow JW, et al. Association between the presence of enterococcal virulence factors gelatinase, hemolysin, and enterococcal surface protein and mortality among patients with bacteremia due to Enterococcus faecalis. Clin Infect Dis 2002; 35: 570-5.

[5] Zareba T, Hryniewicz W. Clinical significance of Enterococcus infection. New Med 1997;4: 30-3.

[6] Heikens E, Bonten MJ, Willems RJ. Enterococcal surface protein Esp isimportant for biofilm formation of Enterococcus faecium E1162. J Bacteriol 2007; 189: 8233-40.

[7] Top J, Willems R, van der Velden S, et al. Emergence of clonal complex 17 Enterococcus faecium in The Netherlands. J Clin Microbiol 2008; 46: 214-9.

[8] Mundy LM, Sahm DF, Gilmore M. Relationships between enterococcal virulence and antimicrobial resistance. Clin Microbiol Rev 2000; 13: 513-22.

[9] Shankar V, Baghdayan AS, Huycke MM et al. Infection-derived Enterococcus faecalis strains are enriched in esp, a gene encoding a novel surface protein. Infect Immun 1999; 67: 193-200.

[10] Borgmann S, Niklas DM, Klare I, et al. Two episodes of vancomycin-resistant Enterococcus faecium outbreaks caused by two genetically different clones in a newborn intensive care unit Int J Hyg Environ Health 2004; 207: 386-9.

[11] Shankar N, Lockatell CV, Baghdayan AS, et al. Role of Enterococcus faecalis surface protein Esp in the pathogenesis of ascending urinary tract infection. Infect Immun 2001; 69: 4366-72.

[12] Kafil HS, Asgharzadeh M. Vancomycin-resistant enterococcus faecium and enterococcus faecalis isolated from education hospital of iran. Maedica J Clin Med 2014; 9: 323-7

[13] CLSI M100-S24. Performance standard for antimicrobial susceptibility testing; Twenty-second informational supplement. 2014; 32(1)

[14] Kafil HS, Mobarez AM, Moghadam MF. Adhesion and virulence factor properties of Enterococci isolated from clinical samples in Iran. Ind J Pathol Microbiol 2013; 56: 238-42.

[15] Kariyama R, Mitsuhata R, Chow JW, et al. Simple and reliable multiplex PCR assay for surveillance isolates of vancomycinresistant enterococci. J Clin Microbiol 2000; 38: 3092-5.

[16] Cheng S, McCleskey FK, Gress MJ, et al. A PCR assay for identification of Enterococcus faecium. J Clin Microbiol 1997; 35 1248-50.

[17] Eaton TJ, Gasson MJ. Molecular screening of Enterococcus virulence determinants and potential for genetic exchange between food and medical isolates. Appl Environ Microbiol 2001; 67: 162835.

[18] Dworniczek E, Kuzko K, Mróz E, et al. Virulence factors and in vitro adherence of Enterococcus strains to urinary catheters. Folia Microbiol (Praha) 2003; 48:671-8

[19] Hammerum AM, Jensen LB. Prevalence of esp, encoding the enterococcal surface protein, in Enterococcus faecalis and Enterococcus faecium isolates from hospital patients, poultry, and pigs in Denmark. J Clin Microbiol 2002; 40: 4396.

[20] Donelli G, Guaglianone E. Emerging role of Enterococcus spp in catheter-related infections: biofilm formation and novel mechanisms of antibiotic resistance. J Vasc Access 2004; 5: 3-9.

[21] Donlan RM. Biofilms: microbial life on surfaces. Emerg Infect Dis 2002; 8: 881-90.

[22] Waar K, Muscholl-Silberhorn AB, Willems RJ, et al. Genogrouping and incidence of virulence factors of Enterococcus faecalis in liver transplant patients differ from blood culture and fecal isolates. J Infect Dis 2002; 185: 1121-7.

[23] Toledo-Arana A, Valle J, Solano C, et al.The enterococcal surface protein, Esp, is involved in Enterococcus faecalis biofilm formation. Appl Environ Microbiol 2001; 67: 4538-45.

[24] Billström H., Lund B, Sullivan A, et al.Virulence and antimicrobial resistance in clinical Enterococcus faecium. Int J Antimicrob Agents 2008; 32: 374-7. 